\title{
System Modeling and Sensitivity Analysis of the Iowa Food-Water-Energy Nexus
}

\author{
V. Raul ${ }^{1}$, L. Leifsson ${ }^{1 *}$, and A. Kaleita ${ }^{2}$ \\ ${ }^{1}$ Department of Aerospace Engineering, Iowa State University, Ames, IA 50011, USA \\ ${ }^{2}$ Departments of Agricultural and Biosystems Engineering, Iowa State University, Ames, IA 50011, USA
}

Received 19 October 2020; revised 11 November 2020; accepted 12 November 2020; published online 31 December 2020

\begin{abstract}
The state of Iowa has long been recognized as a significant contributor of nitrogen loads to the Mississippi river basin. The nitrogen loads are mainly in the form of nitrates arising from high yield agriculture and animal agriculture. With excessive water flowing through the water system of Iowa, the surplus nitrogen in the soil gets carried into the Mississippi river basin and ultimate ly to the Gulf of Mexico, resulting in the generation of a hypoxic zone having a detrimental impact on the environment. Iowa is a leading producer of corn, soybean, animal products, and ethanol; hence, agriculture and animal agriculture are well rooted in its economy. With increasing ethanol demands, high yield agricultural practices, growing animal agriculture, and a connected economy, there is a need to understand the interdependencies of the Iowa food-energy-water (IFEW) nexus. In this work, a model of the IFEW system interdependencies is proposed and used as the basis for a computational system model, which can be used to guide decision-makers for improved policy formation to mitigate adverse impacts of the nitrogen export on the environment and economy. Global sensitivity analysis of the prop osed IFEW system model reveals that the commercial nitrogen application rate for corn and corn yield are the critical parameters affect ing nitrogen surplus in soil.
\end{abstract}

Keywords: food-energy-water nexus, nitrogen export, hypoxic zone, interdependencies, system modeling, sensitivity analysis.

\section{Introduction}

The depletion of dissolved oxygen (hypoxia) in the northern Gulf of Mexico can be linked to nutrient-rich water it receives from the Mississippi river. Nutrients like nitrogen $(\mathrm{N})$ are an important contributor to the formation of the hypoxic zone in the Gulf of Mexico (Lu et al., 2020), having a detrimental environmental and socioeconomic impact. The Midwest corn belt is a major contributor of nitrogen loading to the Mississippi river basin in the form of nitrates $\left(\mathrm{NO}_{3}\right)$ (Burkart and James, 1999).

The Midwest state of Iowa in the US is one of the major producers of corn, soybean, ethanol, and animal products, and known for disproportionately contributing nitrogen loads to the Mississippi river basin (Jones and Schilling, 2019b). Iowa has a unique issue of too much water with little use of irrigation. Consequently, there has been a significant investment in the development of subsurface drainage systems for improving agriculture productivity in Iowa. The drained water flows through Iowa watersheds and exits into major Iowa rivers, which in turn empty into the Mississippi river. Iowa produces most corn in the US, of which almost $57 \%$ of produced corn is used to produce ethanol (Urbanchuk, 2020). Previous studies have predicted that the increased demands of ethanol production could drive corn

${ }^{*}$ Corresponding author. Tel.: (515) 294-6549; fax: (515) 294-3262.

E-mail address: leifur@iastate.edu (L. Leifsson).

ISSN: 2663-6859 print/2663-6867 online

(C) 2020 ISEIS All rights reserved. doi:10.3808/jeil.202000044. production by converting soybean areas to corn (Donner and Kucharik, 2008). Further, the use of nitrogen-based fertilizers by farmers could increase for maximizing crop yield for both biofuel and food production. Nitrogen, however, highly water soluble and so is exported at relatively high rates through the subsurface drainage systems.

Additionally, rising demands for animal protein have enlarged animal agriculture in Iowa, which is also linked to nitrogen sources (Jones and Schilling, 2019b). Agriculture, animal agriculture, and ethanol production are integral to Iowa's economy, with the outcome of increased nitrogen carried through the water system that contaminates Iowa's drinking municipal water (Jones and Schilling, 2019b) and impacts the ecosystem of the Gulf of Mexico. Therefore, there is great incentive to understand the interdependencies the Iowa food-energy-water (IFEW) system to create appropriate policies for the mitigation of the adverse impact on the environment and the economy.

In this work, a model of the IFEW system interdependdencies is proposed which describes the connections of agriculture, animal agriculture, water, energy, and the weather, as well as the exported nitrogen. Furthermore, a macro-scale computational model of the IFEW system is created based on the proposed interdependencies. Global sensitivity analysis using Sobol' indices (Sobol, 2001) is performed on the IFEW system model to reveal which parameters contribute most to the nitrogen export.

The remainder of this paper is structured as follows. The next section describes the interdependencies of IFEW, the proposed IFEW system model, and global sensitivity analysis with 


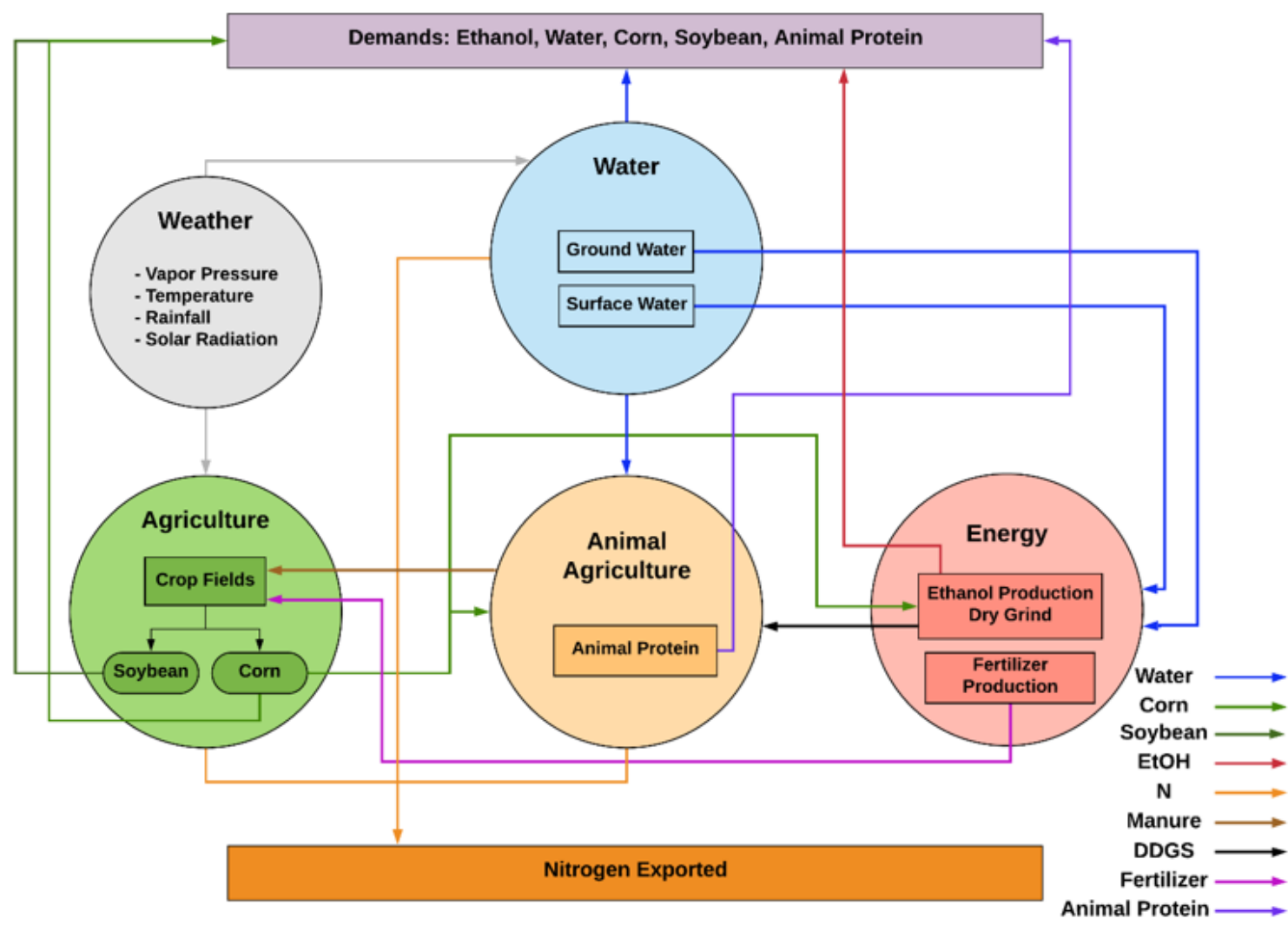

Figure 1. A model of the interdependencies of the Iowa food-energy-water system.

Table 1. Nitrogen Content in Manure and Life Cycle for Livestock Groups Used in Manure N Calculation (Gronberg and Arnold, 2017)

\begin{tabular}{lll}
\hline Livestock Group & Nitrogen in Manure $\left(\mathrm{A}_{\mathrm{MN}}\right)(\mathrm{kg}$ per animal per day) & Life Cycle $(\mathrm{LF})($ days per year) \\
\hline Hog/Pigs & 0.027 & 365 \\
Beef Cattle & 0.15 & 365 \\
Milk Cows & 0.204 & 365 \\
Heifer/Steers $(0.5 \times$ other cattle $)$ & 0.1455 & 365 \\
Slaughter Cattle $(0.5 \times$ other cattle $)$ & 0.104 & 170 \\
\hline
\end{tabular}

Sobol' indices. The following section presents the results of the numerical analysis of the IFEW system. Lastly, conclusions are given and suggestions for future work are outlined.

\section{Methods}

This section introduces the model of the IFEW system interdependencies and the formulation of the system computational model. Global sensitivity analysis based on Sobol' indices is described.

\subsection{IFEW System Interdependencies}

The proposed approach for the IFEW system modeling draws on multidisciplinary analysis and optimization (MDAO) theory (Martins and Lambe, 2013). A similar approach has been implemented in the Water, Energy, and Food security nexus Optimization model (WEFO) developed by Zhang and Vesselinov
(2017). WEFO demonstrated that critical information can be provided to decision-makers and stakeholders to make costeffective decisions for optimal food-energy-water (FEW) management when applied to a hypothetical FEW systems problem.

In this study, the MDAO approach is applied to the IFEW system to model the synergies of the inherently coupled food, water, and energy disciplines with the goal of meeting Iowa's socioeconomic demands. The purpose of the model is to provide critical information regarding the complex interdependencies to enable efficient policy and decision making in Iowa with respect to the environmental impact of the nitrogen export.

The proposed IFEW system model representing individual components of the IFEW system and their interdependencies is shown in Figure 1, including the socioeconomical and environmental constraints. Currently, Iowa holds the first rank in corn, ethanol, red meat, pork, and egg production, and second in soybean production, representing major socioeconomic systems in Iowa (NDEE, 2018; USDA, 2020). The current IFEWs model 
is developed for representing the major socio-economic systems of Iowa and its effect on the flow of nitrates through its watersheds.

In particular, the IFEWs model involves five individual systems representing weather, water, agriculture, animal agriculture, and energy. The weather component predominantly affects the water and agricultural systems through different environmental parameters such as temperature, precipitation, vapor pressure. The weather parameters strongly impact the agriculture system by affecting the corn and soybean yield in the corn belt regions (Westcott and Jewison, 2013). Similarly, precipitation and snowfall determine the amount of surface and groundwater availability. The water system interacts with animal agriculture and energy systems. In animal agriculture, water is consumed as drinking water and service water, whereas the energy system consumes water for ethanol and fertilizer production. The ethanol production produces dry distillers' grain soluble (DDGS) as a byproduct that serves as a premium protein source in animal agriculture. The fertilizer and manure produced from animal agriculture are applied to the corn and soybean fields to produce higher crop yields and most of the produced corn is used for ethanol production. Each system (except the weather) is responsible for meeting socioeconomic demands on corn, soybean, ethanol, water, and food protein. Finally, water flow carries the excess nitrates from agricultural and animal agricultural lands aggregate into the Mississippi river and ultimately into the Gulf of Mexico.

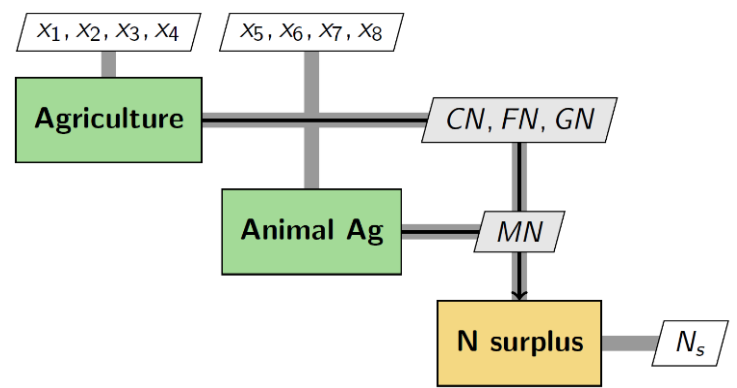

Figure 2. An extended design structure matrix diagram of the proposed Iowa nitrogen export model.

\subsection{IFEW System Computational Model}

The current study concentrates on the development of the nitrogen export model and its interactions with other disciplines. The amount of nitrogen transported through Iowa watersheds chiefly comes from high yield agriculture and animal agriculture operations. Almost $70 \%$ of the Iowa area uses high yield agricultural practices to enhance crop yield with nitrogen fertilizers, especially for corn production (Jones et al., 2019a). Additionally, with increasing demands for animal protein, the animal agricultural operations in Iowa have increased livestock production, such as cattle and hogs. The manure produced by animal agriculture is rich in nitrogen and has been used as a substitute for inorganic fertilizers (Bakhsh et al., 2005). With the widespread availability of manure, high nitrogen fertilization rates create a surplus amount of nitrogen in the soil, which can be carried through the subsurface drainage. For this study, a macro-level nitrogen export system model is developed for the state of Iowa.

An extended design structure matrix (XDSM) diagram (Lambe and Martins, 2012) of the proposed IFEW system computational model is shown in Figure 2, showing the involved systems in calculation of surplus nitrogen $\left(N_{s}\right)$, the flow of data, and the process of calculation. In particular, the input parameters are $x_{i}(i=1, \ldots, 8)$ which are the corn yield $\left(x_{1}\right)$, soybean yield $\left(x_{2}\right)$, rate of commercial nitrogen for corn $\left(x_{3}\right)$, and rate of commercial nitrogen for soybean $\left(x_{4}\right)$, the total hog/pig population $\left(x_{5}\right)$, the number of beef cows $\left(x_{6}\right)$, number of milk cows $\left(x_{7}\right)$, and number of other cattle $\left(x_{8}\right)$ including the population of steers, heifers, and slaughter cattle. The system response parameters are $C N, F N, G N$, and $M N$, where $C N$ represents commercial nitrogen, $M N$ represents nitrogen generated from manure, $F N$ represents nitrogen fixed by soybean crop, and $G N$ represents the nitrogen present in harvested grain.

The proposed nitrogen export model is based on nitrogen budgeting to gain an insight into the nitrate sources in the entire Iowa. The calculation of nitrogen surplus (Ns) is based on the construction of a rough agronomic annual nitrogen budget (Blesh and Drinkwater, 2013; Jones et al., 2019a) given as:

$N s=C N+M N+F N-G N$

where $C N$ is the input from the application of commercial nitrogen, $M N$ is the nitrogen generated from manure, $F N$ is the nitrogen fixed by soybean crop, and $G N$ is the nitrogen present in harvested grain.

The agriculture system receives four input parameters, namely, the corn yield $\left(x_{1}\right)$, soybean yield $\left(x_{2}\right)$, rate of commercial nitrogen for corn $\left(x_{3}\right)$, and the rate of commercial nitrogen for soybean $\left(x_{4}\right)$. The output parameters of the agriculture system are $C N, F N$, and $G N$. The commercial nitrogen $(C N)$ is defined as:

$C N=\left(x_{3} A_{c o r n}+x_{4} A_{\text {soy }}\right) / A$

where $A_{\text {corn }}$ and $A_{\text {soy }}$ represents Iowa corn and soybean acreage whereas $A$ represents the total area under corn and soybean crop. For the current study, the values of the corn and soybean acreages are obtained from (USDA, 2020). The biological nitrogen fixation from the soybean crop is estimated based on relationship provided by Barry et al. (1993) and is given by:

$F N=\left(81.1 x_{2}-98.5\right) A_{\text {soy }} / A$

where $x_{2}$ is the soybean yield in tons per hectare. Lastly, nitrogen exported in the harvested corn and soybean grain is computed to be $6.4 \%$ nitrogen in the soybean seed and $1.18 \%$ nitrogen in the corn seed (Blesh and Drinkwater, 2013) and is defined as:

$G N=\left(x_{1}\left(\frac{1.18}{100}\right) A_{c o r n}+x_{2}\left(\frac{6.4}{100}\right) A_{\text {soy }}\right) / A$

For this work, the corn and soybean data are obtained from 
the USDA $2008 \sim 2019$ reports (USDA, 2020). The corn yield varies from 137 to 203 bushels/acre (bu/acre), whereas the soybean yield varies from 45 to $60 \mathrm{bu} / \mathrm{acre}$. The nitrogen application rate for corn is obtained from the Iowa State University extension guidelines (Sawyer, 2018). The range of nitrogen application rate for corn is chosen to be from 155 to $215 \mathrm{~kg} / \mathrm{hectare}$ $(\mathrm{kg} / \mathrm{ha})$ considering the average nitrogen rates for corn following corn and corn following soybeans in Iowa. The range of nitrogen application rate for soybean is chosen to be from $5 \mathrm{~kg} / \mathrm{ha}$ to $30 \mathrm{~kg} / \mathrm{ha}$ based on the fertilizer use and price data between $2008 \sim 2018$ (USDA, 2019) with an average rate of $17.7 \mathrm{~kg} / \mathrm{ha}$ and a standard deviation of $4.8 \mathrm{~kg} / \mathrm{ha}$. The acreage under corn and soybean are obtained from USDA 2019 statistics report (USDA, 2020).
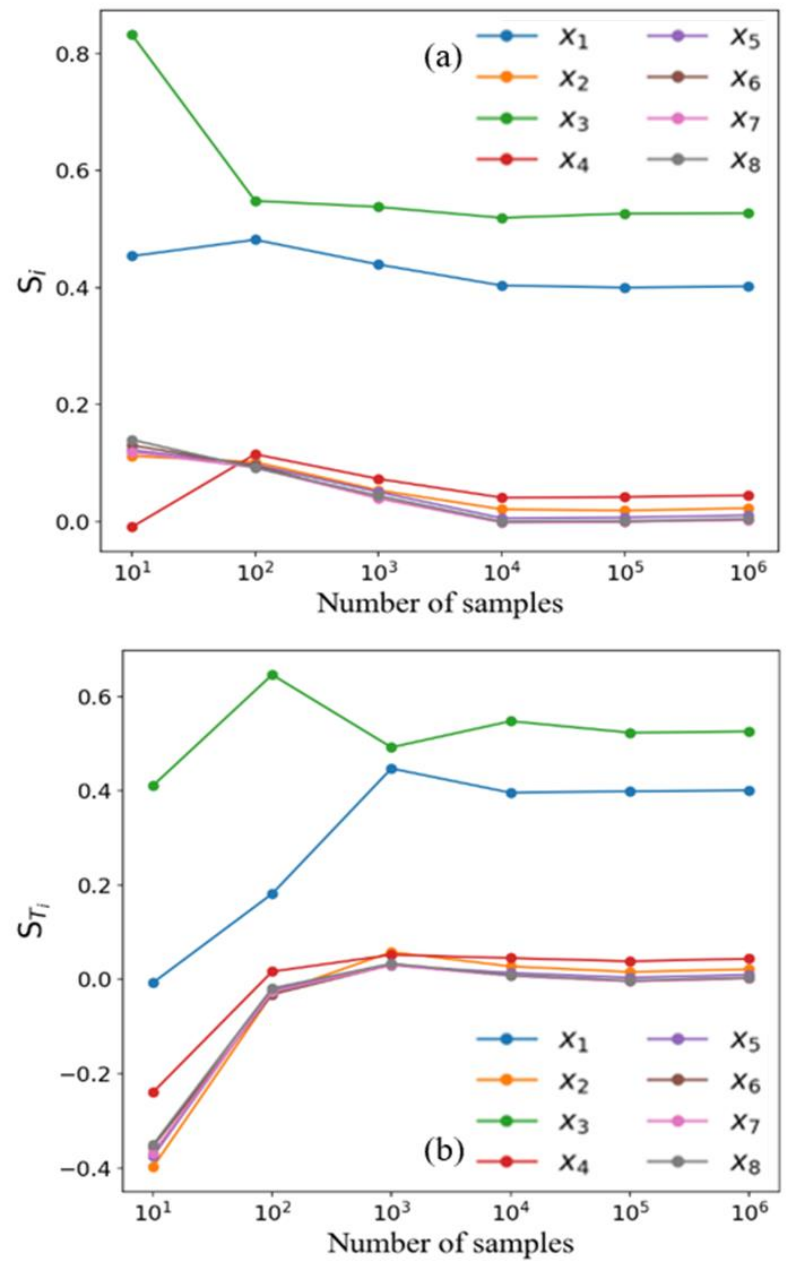

Figure 3. Convergence of the Sobol' indices of the nitrogen export model: (a) the first-order Sobol' indices and (b) the total-effect Sobol' indices.

The animal agriculture system receives four input parameters, namely, the total hog/pig population $\left(x_{5}\right)$, number of beef cows $\left(x_{6}\right)$, number of milk cows $\left(x_{7}\right)$, and the number of other cattle $\left(x_{8}\right)$ which includes the population steers, heifers, and slaughter cattle. According to USDA (2020), Iowa holds first rank in red meat, pork, and egg production, however, the amount of nitrogen in poultry is much less than hogs and cattle. Thus, to keep the minimum number of parameters in our system model, only hog/pig and cattle populations are used for the MN calculation. The annual manure nitrogen contribution of each animal type is given by (Gronberg and Arnold, 2017):

$M N_{\text {animal }}=P A_{M N} L F$

where $P, A_{M N}$ and $L F$ are livestock group population, nitrogen in animal manure and life cycle of animal. Table 1 provides the numerical values of the parameters used for calculation of $M N$ for each livestock group. The total $M N$ contribution is then normalized using area $A$ before using it for the nitrogen surplus calculation (5) and is given as:

$M N=\left(M N_{\text {Hog/pigs }}+M N_{\text {Beef cattle }}+M N_{\text {Milk cow }}+M N_{\text {other cattle }}\right) / A$

For this work, the Iowa animal population data of 2012 is obtained from USGS (Gronberg and Arnold, 2017). According to this dataset, in 2012, the Iowa hog/pig population was approximately 20.5 million, whereas beef cattle, milk cows, and other cattle populations (see Table 1) were approximately 734 thousand, 316 thousand, and 2.8 million, respectively.

\subsection{Global Sensitivity Analysis}

Global sensitivity analysis (GSA) of the nitrogen export model is conducted to understand the contribution of each input parameter on the model output. In this work, Sobol' indices (Sobol, 2001) are used for the GSA. Sobol' analysis uses the variance decomposition approach to provide the first-order and total-effect sensitivity indices of input variables (Saltelli et al., 2008). These indices can be used for understanding the sensitivities of individual parameters and their interactions with other parameters on the model output.

Consider the model response $y=f(\mathbf{x})$ as a function of vector $\mathbf{x}$ with $n$ parameters. Then, the total variance $\mathbb{V}(y)$ in any model response $y$ can be decomposed as (Saltelli et al., 2008):

$\mathbb{V}(y)=\sum_{i=1}^{n} V_{i}+\sum_{i=1}^{n} \sum_{i<j}^{n} V_{i j}+\ldots+V_{12 \ldots n}$

where $V_{i}$ is the variance contribution of $i^{\text {th }}$ design variable to total variance $\mathbb{V}(y), V_{i j}$ is the variance contribution from $i^{\text {th }}$ and $j^{\text {th }}$ variables together to $\mathbb{V}(y)$. The Sobol' indices can be obtained by dividing (7) by $\mathbb{V}(y)$ to obtain:

$1=\sum_{i=1}^{n} S_{i}+\sum_{i}^{n} \sum_{i<j}^{n} S i_{j}+\ldots+S_{12 \ldots n}$

where $S_{i}$ represent first-order index of $i^{\text {th }}$ variable given as:

$S_{i}=\frac{V_{i}}{\mathbb{V}(y)}$ 
and $S_{T i}$ is a total-effect index of the $i^{\text {th }}$ variable given as:

$S_{T i}=1-\frac{\mathbb{V}\left(\mathbb{E}\left(y \mid \mathbf{x}_{\sim i}\right)\right)}{\mathbb{V}(y)}$

where $\mathrm{x}_{\sim i}$ represents the set of all variables except $x_{i}$. The totaleffect index $S_{T i}$ accommodates the total contribution of variable $x_{i}$ to $\mathbb{V}(y)$ involving first-order effect plus higher order effects due to interaction with variables. The interaction effect can be computed by taking the difference between $S_{T i}$ and $S_{i}$ indicating presence of interaction effect with other variables. The computation of the Sobol' indices is typically performed using a sampling-based numerical procedure (Saltelli et al., 2008).

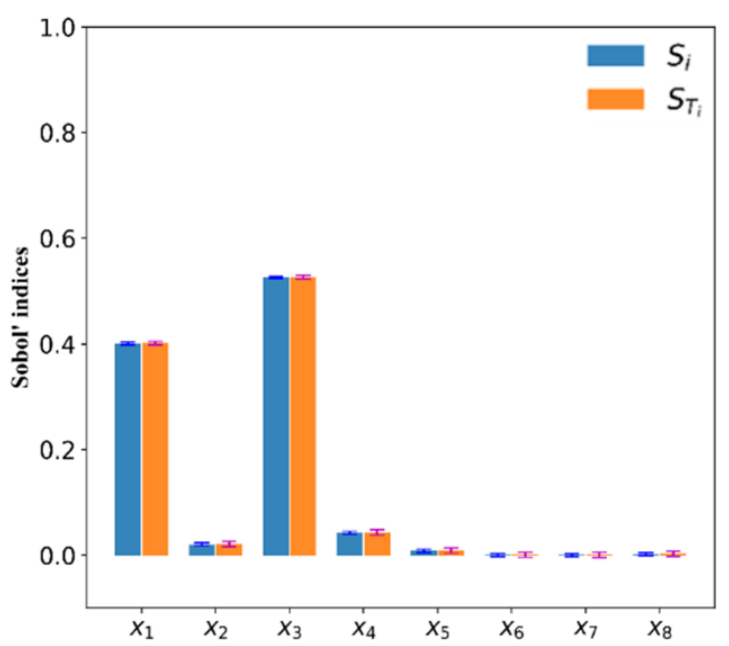

Figure 4. Sobol' indices of the nitrogen export model response.

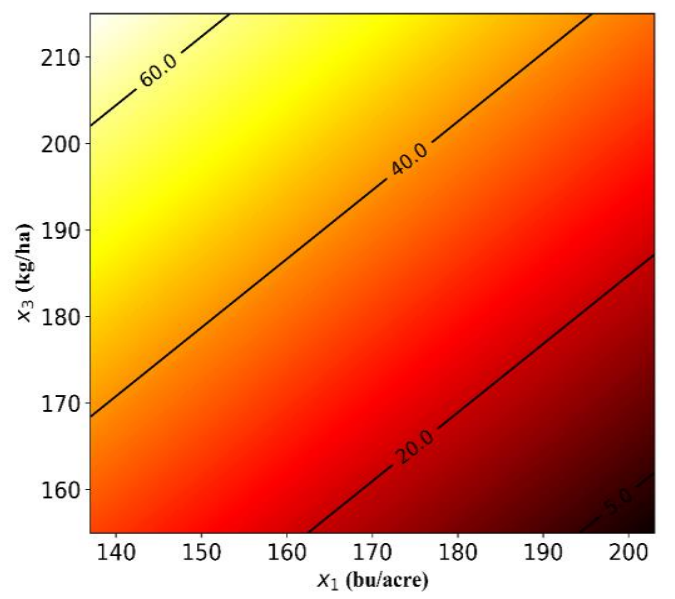

Figure 5. Contours of nitrogen surplus over the corn yield $\left(x_{1}\right)$ and corn nitrogen application rate $\left(x_{3}\right)$.

\section{Results}

This section presents the results of the GSA of the nitrogen export model proposed in this paper using Sobol' indices. In this work, samples are generated using Latin hypercube sampling (LHS) (McKay et al., 2000) within the respective input parameter ranges. The parameter ranges required for the agricultural system model are given in Section 2.2. The parameters used in the animal agriculture model vary between the lower range based on the 2012 Iowa animal population data (Gronberg and Arnold, 2017), and the upper range is considered 1.5 times the lower range for each livestock group.

The number of samples required for accurate Sobol' indices estimation is obtained by conducting a convergence study. Figure 3 shows the convergence of $S_{i}$ and $S_{T i}$ over the number of samples, which indicates their convergence after $10^{5}$ samples. The Sobol' index calculations are then repeated 30 times to obtain the mean value of the Sobol' indices for each parameter and their respective standard deviations. It should be noted that the negative values of Sobol' indices are due to a numerical error in estimation that typically arise when the sensitivity indices are close to zero (Saltelli et al., 2008).

Figure 4 shows the GSA of the nitrogen export model response with respect to the model inputs. The most influential model parameters are $x_{3}$ (nitrogen application rate for corn) and $x_{1}$ (corn yield), predominantly affecting the variation in nitrogen surplus values. This is an expected result considering corn acreage in Iowa and the high rate of nitrogen application. The parameters corresponding to soybean $x_{4}$ (nitrogen application rate for soybean) and $x_{2}$ (soybean yield) slightly affect the nitrogen surplus values, whereas the parameters involved with animal agriculture $\left(\mathrm{x}_{i}, i=5, \ldots, 8\right)$ have minimal effect on the nitrogen surplus values. The difference between the total and first-order effects indicates the presence of interaction effects with other parameters. It should be noted that the current results do not indicate any interaction effects between model parameters. This is mainly due to the feedforward design of the nitrogen export model and the modeling equations involved in the computation of nitrogen surplus showing current model limitations.

The effect of the most influential parameters $x_{1}$ and $x_{3}$ on the nitrogen surplus amount is shown in Figure 5, which is obtained by varying those parameters while keeping all other variables fixed $\left(x_{2}=55 \mathrm{bu} / \mathrm{acre}, x_{4}=15.75 \mathrm{~kg} / \mathrm{ha}\right.$, and $x_{\mathrm{i}}, i=5, \ldots, 8$, fixed to the 2012 Iowa animal population data). It is observed that the entire contour plot shows a positive nitrogen surplus. The low yield with a high nitrogen application rate for corn creates a high nitrogen surplus in the soil shown by the hotspot region in the left top corner of Figure 5. Such a situation could arise if corn yield drastically drops due to extreme weather events during the growing season. Ideally, a high corn yield with a lower nitrogen application rate would reduce the nitrogen surplus available in the soil as seen from the darker region in Figure 5.

A further investigation of model response is conducted by exploring similar parameter ranges as used in the GSA. A total $10^{5}$ samples are used to compute the average contributions of $C N, F N, G N$, and $M N$ to the nitrogen surplus (Figure 6). The total average nitrogen input $(C N+M N+F N)$ to the soil is found to be $213.4 \mathrm{~kg} / \mathrm{ha}$, obtained by cumulative contribution from $C N$, $M N$ and $F N$ whereas, $G N$ of $171.8 \mathrm{~kg} / \mathrm{ha}$ is removed from the 
soil through grain harvest generating an average $N$ surplus of $41.6 \mathrm{~kg} / \mathrm{ha}$. The corn harvest contributes approximately $45.7 \%$ to total $G N$, whereas almost $53.3 \%$ of $G N$ is contributed by the soybean harvest (see Figure 6).

Out of the total nitrogen input to the soil, the average contribution from $M N$ is found to be $9.5 \%(M N=20.2 \mathrm{~kg} / \mathrm{ha})$. Commercial nitrogen has the highest contribution of $54.8 \%$ to the soil nitrogen input $(C N=117.1 \mathrm{~kg} / \mathrm{ha})$ out of which is approximately $6 \%$ of $C N$ is contributed by soybean farmlands and $94 \%$ of $C N$ is contributed by the corn fields. The fixation nitrogen from soybean contributes $35.7 \%$ to soil nitrogen input $(F N=$ $76.1 \mathrm{~kg} / \mathrm{ha})$.

Overall, the GSA of the IFEW system nitrogen export model shows that the rate of commercial nitrogen application to corn fields and corn yield are the two most influential parameters driving overall nitrogen loads in Iowa. Soybean farming minimally affects the nitrogen surplus amount; however, soybean farming contributes almost $36 \%$ of the total soil nitrogen input. The animal agriculture parameters negligibly affect the nitrogen surplus amount; however, further investigation is needed at the county- or watershed-level as it was shown in previous studies that the animal agriculture does drive nitrogen loads at the county-level (Jones et al., 2019a). Thus, further development and investigation of the county- or watershed-levels nitrogen export model is needed. Additionally, the current nitrogen export model does not show interaction effects between individual parameters indicating a need for improved nitrogen export modeling.

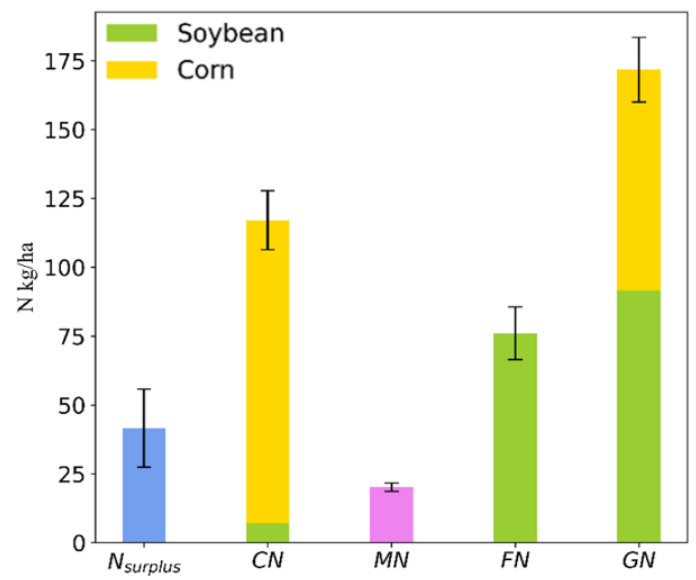

Figure 6. Contributions of $C N, F N, G N$, and $M N$ to the nitrogen surplus.

\section{Conclusions}

In this work, a system model of the Iowa food-energy-water (IFEW) is proposed to better understand the system interdependencies impacting the environment and Iowa's economy. Specifically, a macro-level nitrogen export model for Iowa is implemented to quantify nitrogen surplus in soil. The understanding of sensitivities of model input parameters to the nitrogen export model response is obtained using global sensitivity analysis with Sobol' indices.
It is observed that the commercial nitrogen application rate for corn and corn yield are the most influential parameters affecting variation in soil nitrogen surplus, whereas the comercial nitrogen rate for soybean and soybean yield has minimal effect. The animal population parameters under animal agriculture have a negligible impact on variation in soil nitrogen surplus. Although, the parameters connected to soybean farming and animal agriculture show lower sensitivities to nitrogen surplus variation, they substantially contribute to soil nitrogen input. Further, sensitivity analysis does not show interaction effects between input parameters, indicating the need for improved nitrogen modeling for Iowa.

In future work, the proposed systems in the IFEW system framework will be further developed for Iowa, including detailed modeling of ethanol production, water flow, and weather models. The weather model will provide the impact of weather parameters on the IFEW system, which will be helpful in generating different scenarios such as drought and flooding. Furthermore, county- or watershed-level models will be generated for providing a more accurate contribution of regional nitrogen load from Iowa.

Acknowledgments. This material is based upon work supported by the United States National Science Foundation under grant no. 17395 51 .

\section{References}

Bakhsh, A., Kanwar, R.S., and Karlen, D.L. (2005). Effects of liquid swine manure applications on $\mathrm{NO}_{3}-\mathrm{N}$ leaching losses to subsurface drainage water from loamy soils in Iowa. Agriculture, Ecosystems \& Environment., 109(1-2), 118-128. https://doi.org/10.1016/j.agee.2005. 01.018

Barry, D.A.J., Goorahoo, D., and Goss, M.J. (1993). Estimation of nitrate concentration in groundwater using a whole farm nitrogen budget. American Societh of Agronomy, Crop Science Society of America, and Soil Science Society of America, 22: 767-775. https://d oi.org/10.2134/jeq1993.00472425002200040019x

Blesh, J. and Drinkwater, L.E. (2013). The impact of nitrogen source and crop rotation on nitrogen mass balances in the Mississippi River Basin. Ecological Applications, 23(5), 1017-1035. https://doi.org/1 0.1890/12-0132.1

Burkart, M.R. and James, D.E. (1999). Agricultural-nitrogen contributions to hypoxia in the Gulf of Mexico. Journal of Environmental Quality, 28(3), 850-859. https://doi.org/10.2134/jeq1999.00472425 $002800030016 x$

Donner, S.D. and Kucharik, C.J. (2008). Corn-based ethanol production compromises goal of reducing nitrogen export by the Mississippi River. Proceedings of the National Academy of Sciences, 105(11), 4513-4518. https://doi.org/10.1073/pnas.0708300105

Gronberg, J.M. and Arnold, T.L. (2017). County-level estimates of nitrogen and phosphorus from animal manure for the conterminous United States, 2007 and 2012 (No. 2017-1021). US Geological Survey, https://doi.org/10.3133/ofr20171021

Jones, C.S., Drake, C.W., Hruby, C.E., Schilling, K.E., and Wolter, C.F. (2019a). Livestock manure driving stream nitrate. Ambio, 48(10), 114 3-1153. https://doi.org/10.1007/s13280-018-1137-5

Jones, C.S. and Schilling, K.E. (2019b). Iowa Statewide Stream Nitrate Loading: 2017-2018 Update. The Journal of the Iowa Academy of Science, 126(1), 6-12. https://doi.org/10.17833/126-02.1

Jones, C.S., Seeman, A., Kyveryga, P.M., Schilling, K.E., Kiel, A., 
Chan, K.S., and Wolter, C.F. (2016). Crop rotation and Raccoon River nitrate. Journal of Soil and Water Conservation, 71(3), 206-2 19. https://doi.org/10.2489/jswc.71.3.206

Lambe, A.B., and Martins, J.R. (2012). Extensions to the design structure matrix for the description of multidisciplinary design, analysis, and optimization processes. Structural and Multidisciplinary Optimization, 46(2), 273-284. https://doi. org/10.1007/s00158-012-0763-y

Lu, C., Zhang, J., Tian, H., Crumpton, W.G., Helmers, M.J., Cai, W.J., and Lohrenz, S.E. (2020). Increased extreme precipitation challenges nitrogen load management to the Gulf of Mexico. Communications Earth \& Environment, 1(1), 1-10. https://doi.org/10.1038/s43247020-00 020-7

Martins, J.R., and Lambe, A.B. (2013). Multidisciplinary design optimization: a survey of architectures. AIAA journal, 51(9), 2049-2075. https://doi.org/10.2514/1.J051895

McKay, M.D., Beckman, R.J., and Conover, W.J. (2000). A compareson of three methods for selecting values of input variables in the analysis of output from a computer code. Technometrics., 42(1), 5561. https://doi.org/10.1080/00401706.2000.10485979

NDEE-Energy and Assistance Division. (2018). Ethanol Facilities Capacity by State. https://neo.ne.gov/

Sawyer, J.E. (2018). Nitrogen use in Iowa corn production. Crop 3073. Iowa State Univ. Ext., Ames. https://store.extension.iastate.edu/ Pro-
duct/Nitrogen-Use-in-Iowa-Corn-Production

Saltelli, A., Ratto, M., Andres, T., Campolongo, F., Cariboni, J., Gatelli, D., and Tarantola, S. (2008). Global Sensitivity Analysis: the primer. John Wiley \& Sons, West Sussex, England.

Sobol, I.M. (2001). Global sensitivity indices for nonlinear mathematical models and their Monte Carlo estimates. Mathematics and computers in simulation, 55(1-3), 271-280. https://doi.org/10.1016/S0378-475 4(00)0 0270-6

Urbanchuk, J.M. (2020). Contribution of the renewable fuels industry to the economy of Iowa. Agricultural and Biofuels Consulting. https://iowarfa.org/wp-content/uploads/2020/03/2019-Iowa-Econo mic-Impact-Final-2.pdf

United States Department of Agriculture. (2019). Fertilizer Use and Price. https://www.ers.usda.gov/data-products/fertilizer-use-and price/ United States Department of Agriculture. (2020). National agricultural statistics service quick stats. https://quickstats.nass.usda.gov/

Westcott, P.C., and Jewison, M. (2013). Weather Effects on Expected Corn and Soybean Yields, Washington DC: USDA Economic Research Service FDS-13g-01.

Zhang, X., and Vesselinov, V.V. (2017). Integrated modeling approach for optimal management of water, energy and food security nexus. Advances in Water Resources, 101, 1-10. https://doi.org/10.1016/j.a dvwatres.201 6.12.017 